\title{
Exploring Japanese Student Attitude Change to Gendered Interactions
}

\author{
Robert W. Long III
}

\begin{abstract}
Of the many sociolinguistic issues around the world, shyness and hesitation phenomenon are the most serious issues for many Asian youth, particularly in Japan. This study discusses the piloting and development of a gender fluency survey based on three factors: personality traits, communicative competence and morale. It explores Japanese university students' attitudes concerning their behavior and interactions and their desire for more gendered interactions. The overall study examined the interactions of three groups of male students. These 66 discussions were transcribed and form the Longitudinal Japanese University Student Corpus (LJUSC). The study had two female participants interact, oneby-one with male participants. For each group, the interactions took place over six weeks with the two female participants switching roles on a weekly basis. Participants were given the survey before their discussions and again after the three weeks of their own discussions. The research questions focused on possible significant differences between the pre-survey and post-survey results, and if the results from the post-survey indicated a more positive outlook about gendered discussions. Results showed no significant difference between the pre- and post-survey results, but the participants were more positive about having follow-up discussions, and in sharing ideas without hesitation. Participants also felt that they had paid attention to what had been said, and had achieved their own goals. Recommendations focus on teachers providing more varied and challenging interactions for students to become more motivated when talking to the opposite sex.
\end{abstract}

Index Terms-Hesitation phenomenon, shyness, gender discussions, attitudes.

\section{INTRODUCTION}

In Asia and in Japan, one of the many sociolinguistic challenges has been that of shyness, in particular with the genders refusing to interact and form relationships. Some have even described the phenomenon as a "gender war:” It has been a topic that has been discussed in the popular media, both in Japan and abroad. ${ }^{1}$ One survey showed that $34 \%$ of Japanese men are afraid of female colleagues: Men's fear was based on the perception that women tended to gossip, to form rivalries, or to females being deemed bossy or annoying, and to how women were thought to conspire against superiors. ${ }^{2}$ Of course, Japanese women also have their own perceptions and complaints about society's expectations and roles as well as the gender inequality in pay, promotions, and appreciation.

Furthermore, this gendered antipathy is so widespread that $40 \%$ of males describing themselves as virgins; in short,

Manuscript received December 20, 2017; revised February 20, 2018.

Robert Long is with Hiroshima Shudo University, Japan (e-mail: robertwilliamlong@gmail.com). both genders find it difficult and stressful to initiate discussions with the opposite sex, and so see simple discourse as pragmatically challenging. When the genders do have to communicate with each other, they often fail to fluently express their ideas effectively, resulting in perceived or actual negative outcomes. This reinforces and fuels a poor self-esteem and reluctance to interact with the opposite sex. With more isolation, negative stereotypes remain unchallenged.

In short, shyness and hesitation phenomenon are contributing factors in Japan's depopulating crisis, which is causing huge economic and social problems for the nation. The role of gender as a potent, social organizing principle is important in that this one variable can configure organizational power dynamics, identities and relationships. So, in order to better understand the attitudes of how Japanese women and men view each other, this study discusses the piloting and development of a gender fluency survey based on three factors: personality traits, communicative competence, and morale. The study explores, in particular, Japanese university students' attitudes concerning their own behavior and interactions and their desire for more gendered interactions.

\section{REVIEW OF LITERATURE}

\section{A. Gender Shyness}

According to [1] $48.7 \%$ of the people in the United States consider themselves shy; however, one of the issues in researching the concept of shyness is that the construct is rather vague and subjective. According to [2] shyness has been defined in over a dozen ways [3] described shyness as the avoidance of social interaction due to timidness or the withdrawal from nature whereas [2] defined shyness as an "affective-behavioral syndrome characterized by social anxiety and interpersonal inhibition that results from the prospect or presence of interpersonal evaluation” (p. 30). Shyness, which is a label for a broad construct of social withdrawal, is associated with a wide range of negative adjustment outcomes in childhood and adolescence [4]. According to [5] more empirical evidence links shyness with internalizing problems such as loneliness, anxiety, depressive symptoms, peer-relationships difficulties (e.g., peer rejection, victimization) and other problems at school (e.g., negative teacher-child relationships, poorer academic achievement).

Ref. [6] examined pauses and verbal dysfluencies as an indication of speaking anxiety. The authors investigated whether a slower rate of speech or longer period of silence were more prevalent in high-speech subjects than in their low-anxiety counterparts. In examining the categories of pauses, pause-length, verbal errors (corrections, distortions, 
fragments, repetitions) and delaying verbalizations, Lewin found that the measures of state anxiety immediately before and during the speech task did not correlate with dysfluencies or pauses.

In regard to Japanese society, [7] states that around $10 \%$ of individuals in Japan can be characterized as being shy in all situations [8] found from their research that cultural temperaments determine shyness to some degree, and may directly impact shyness, but there could be other explanations such as culture is a mediator for shyness or that shyness is a mediator or moderator for culture. Their conclusion is that social changes may be influencing a shift in cultural dimensions and as a result social behavior. One of the issues in shyness studies is to specifically examine how participants view their own conversational competency in a series of gendered interactions.

Another issue has been that over the past decade, women have become far more independent and outspoken in most countries throughout the world. While there has been tremendous research on the issue of power and on which gender tends to dominate discourse, a second and more important issue, as [9] note, relates to communication anxiety for both genders. Understanding which gender is more uncomfortable with the interaction, (even if he or she is dominating the discourse) and how this leads to more dysfluency is also important to study.

\section{THE STUDY}

\section{A. Rationale}

To better understand how both males and females view each other, it is important to elicit student responses about the opposite sex before and immediately after interactions that spanned three-week period.

\section{B. Research Aims}

1. Are there significant differences between the presurvey and post-survey results?

2. Did the results from the post-survey indicate a more positive outlook about gendered discussions?

Null hypotheses state that there will be no significant differences between the two surveys and that no variables will reflect a more positive outlook about gendered discussions.

\section{Survey Development}

\section{1) Item generation}

Three previous surveys were used to identify factors and variables: the Five Factor Model $(\mathrm{FFM})^{3}$, the Profile of Social Moods 2 (POMs) [10] and a survey based on PM Leadership theory [11] that was adapted for English language teaching [12]. For the first construct of personality traits, five variables were considered: First, openness to experience, which involved the trait of curiosity, in which asked how eager or interested students were in talking with the opposite sex. Second, the variable conscientiousness took into account the students ability to listen, share ideas, give equal time when talking, and to conclude the discussion in a pleasant manner. For the third variable, extraversion, which involves the traits of sociability, acceptance, and candidness, questions were devised concerning how talkative participants were, how they felt when interacting with the opposite sex, and how easily it was to express emotions and relate to each other.

The fourth variable was that of agreeableness, which was defined as the tendency to be compassionate and cooperative rather than being suspicious or antagonistic towards others. High agreeableness is often seen as naïve or submissive whereas low agreeableness is associated with competitive or challenging people, which might be viewed as untrustworthy. This variable had two traits, likeability and friendliness with questions that focused on how the opposite sex liked the participant, and how easy it was to get along with them.

The last variable was that of neuroticism, which was the tendency to experience unpleasant emotions easily, such as anger, anxiety, or depression. Neuroticism is associated with one's degree of emotional stability and impulse control. A high need for stability will be seen in a stable and calm personality, but this can be interpreted as being uninspiring or unconcerned. This variable has two traits: tension and social discomfort, which takes into account any uncomfortable feelings the participants might have and if there were long pauses and silence when interacting with them.

The second construct, communicative competence, involves the variables of strategic competency, (which incorporates the traits of initiation, facilitation), pragmatism (etiquette), and communicative ability (taking into account fluency, nonverbal behavior, and comprehension).

TABLE I: DESCRIPTIVE RESULTS FOR PILOT SURVEY

\begin{tabular}{|l|l|}
\hline Question Item & Average \\
\hline Follow & 2.15 \\
\hline Interrupt & 2.02 \\
\hline Share & 2.16 \\
\hline Tension & 2.28 \\
\hline Conclude & 2.13 \\
\hline Like you & 2.71 \\
\hline Rejection & 2.73 \\
\hline Questions & 2.43 \\
\hline Relate to & 2.65 \\
\hline Talkative & 2.57 \\
\hline Friendly & 2.35 \\
\hline Good time & 2.03 \\
\hline Not shy & 2.61 \\
\hline Equal time & 2.28 \\
\hline Uneasy & 2.48 \\
\hline Long pauses & 2.59 \\
\hline Easy to start & 2.56 \\
\hline Express & 2.43 \\
\hline Pay attention & 2.02 \\
\hline Long reply & 2.38 \\
\hline Nonverbal & 2.32 \\
\hline Understand & 2.72 \\
\hline Confidence & 2.9 \\
\hline Common Interests & 2.41 \\
\hline Goals & 2.55 \\
\hline Shows interests & 2.21 \\
\hline How many men/ women you talk to & 4.08 \\
\hline $\begin{array}{l}\text { How many relationships with men/women do } \\
\text { you have? }\end{array}$ \\
\hline How interested & 4.44 \\
\hline 1 = agree a lot, 4 disagree a lot, 5 no opinion & 6.16 \\
\hline
\end{tabular}

The third construct is that of morale, which was based on [11] survey on PM theory. It focused on performative behavior and motivational behavior and its overall impact on morale. For this survey, there are two variables, 
confidence, which takes into consideration L2 usage, and inhibition while the variable of satisfaction takes into consideration goal achievement and motivation, see Appendix A, for the survey schematic.

\section{Piloting}

Due to the limited amount of time which prevented a factor analysis of the survey being done, piloting was initiated involving 309 participants; the descriptive statistics are shown below in Table I.

\section{E. Procedures}

Male participants and the two females were selected based on their test scores (see Table II), which provided a relatively similar level of proficiency as well as the acknowledgment that they did not know the other people in their group.

There were three groups of male participants. Discussions took place in during one hour on Wednesday, and on the following week, the males met with the next female and discussed different topics for a total of 18 weeks. Participants did sign permission forms allowing for their discussions to be videotaped and transcribed. Also during the first session, students filled out the pre-discussion survey and then after the last session, they filled out the post-discussion survey, see Table II.

TABLE II: SCORES FOR LOWER PROFICIENCY STUDENTS

\begin{tabular}{|c|c|}
\hline Test & Score \\
\hline TOEIC & $440-550$ \\
\hline Eiken 英検 & 2 級 \\
\hline IELTS & $3.0-4.0$ \\
\hline TOEFL IBT & $42-55$ \\
\hline TOEFL ITP & $272-450$ \\
\hline TOEFL PBT & $463-480$ \\
\hline TOEFL CBT & $143-157$ \\
\hline
\end{tabular}

\section{F. Discussion Format}

In order to more accurately measure issues relating to fluency instead of conversational management, subjects were asked to follow, in as much as possible, a three-topic format. The first issue was based on shared interests, in order to find areas of commonality, whereas the second was aimed at gathering information related to these shared interests. The third topic, based on cognitive loading, posed a difficult question or issue that was related to the first topic. If students finished the topic, they could move on to the next one on the list.

\section{G. 2016 Corpus / Transcripts}

The interactions were transcribed into one corpus, the longitudinal Japanese University Student Corpus (LJUSC) ${ }^{4}$. The transcripts were manually transcribed, beginning in May through November 2016. The videos averaged around 10 minutes long. The videos and transcripts make up a total of 65 transcripts, which contains 71,431 words. The transcripts provide a comprehensive picture of students' fluency and dysfluency over a three-week period, thus providing a reliable data set for Japanese shyness and minimal responses.

\section{RESUltS}

In comparing the first 26 items for the pre- and postinterview surveys, no significance was noted $t(25)=$ $1.11743, \mathrm{p}<0.2744$, which proves the first hypothesis. The pre-discussions surveys, students only showed relatively high agreement for three items: 1,2 , and 26, relating to being motivated for follow-up discussions, not interrupting and being rude, and showing interest when the woman/man is talking, see Table III.

TABLE III: PRE-SURVEY AND POST-SURVEY RESULTS

\begin{tabular}{|c|c|c|c|c|}
\hline \multirow[t]{2}{*}{ Variables } & \multicolumn{2}{|c|}{ Pre-survey } & \multicolumn{2}{|c|}{ Post-survey } \\
\hline & Average & $\begin{array}{l}\text { \# of No } \\
\text { opinions }\end{array}$ & Average & $\begin{array}{l}\text { \# of No } \\
\text { opinions }\end{array}$ \\
\hline 1. Follow up talks & 1.75 & 1 & 1.66 & 1 \\
\hline 2. Tries not interrupt & 1.69 & 0 & 1.41 & 0 \\
\hline 3. Shares ideas & 1.92 & 0 & 1.58 & 0 \\
\hline $\begin{array}{l}\text { 4. Some tension in } \\
\text { discussions }\end{array}$ & 1.81 & 2 & 2.41 & 1 \\
\hline 5.Concludediscussions & 1.91 & 1 & 1.83 & 0 \\
\hline $\begin{array}{l}\text { 6. Thinks partner likes } \\
\text { him/her }\end{array}$ & 2.22 & 4 & 2.41 & 2 \\
\hline $\begin{array}{l}\text { 7. Feels some } \\
\text { rejection }\end{array}$ & 2.75 & 5 & 3.00 & 1 \\
\hline $\begin{array}{l}\text { 8. Tries hard to ask } \\
\text { questions }\end{array}$ & 2.15 & 0 & 2.41 & 1 \\
\hline 9. Easy to relate to & 2.69 & 0 & 2.25 & 0 \\
\hline 10. You were talkative & 2.23 & 1 & 2.33 & 1 \\
\hline 11. You were friendly & 2.15 & 0 & 2.33 & 2 \\
\hline $\begin{array}{l}\text { 12. You had a good } \\
\text { time }\end{array}$ & 1.90 & 2 & 1.83 & 1 \\
\hline 13. You were not shy & 2.53 & 0 & 2.58 & 0 \\
\hline $\begin{array}{l}\text { 14. Equal time in } \\
\text { talking }\end{array}$ & 2.00 & 0 & 2.16 & 2 \\
\hline 15. You felt uneasy & 2.27 & 2 & 2.75 & 1 \\
\hline $\begin{array}{l}\text { 16. There were long } \\
\text { pauses }\end{array}$ & 2.60 & 3 & 3.00 & 2 \\
\hline $\begin{array}{l}\text { 17. Easy to start } \\
\text { discussion }\end{array}$ & 2.18 & 2 & 2.25 & 1 \\
\hline $\begin{array}{l}\text { 18. It was difficult to } \\
\text { express yourself }\end{array}$ & 2.27 & 2 & 2.75 & 2 \\
\hline 19. You paid attention & 1.92 & 0 & 1.66 & 0 \\
\hline $\begin{array}{l}\text { 20. You shared } \\
\text { opinions }\end{array}$ & 2.30 & 0 & 2.50 & 1 \\
\hline $\begin{array}{l}\text { 21. You smiled \& } \\
\text { attentive }\end{array}$ & 2.00 & 1 & 1.81 & 1 \\
\hline $\begin{array}{l}\text { 22. Easy to understand } \\
\text { participant }\end{array}$ & 2.84 & 0 & 2.33 & 0 \\
\hline $\begin{array}{l}\text { 23. You were } \\
\text { confident }\end{array}$ & 2.75 & 1 & 2.58 & 0 \\
\hline $\begin{array}{l}\text { 24. It was difficult in } \\
\text { finding common } \\
\text { interests }\end{array}$ & 2.10 & 3 & 3.00 & 2 \\
\hline $\begin{array}{l}\text { 25. You achieved your } \\
\text { goals }\end{array}$ & 2.54 & 2 & 2.16 & 1 \\
\hline $\begin{array}{l}\text { 26. You showed some } \\
\text { interest. }\end{array}$ & 1.75 & 1 & 2.25 & 2 \\
\hline $\begin{array}{l}\text { 27. How many } \\
\text { women/men do you } \\
\text { talk to for } 10 \text { minutes } \\
\text { or more each day? }\end{array}$ & 2.46 & $\begin{array}{l}- \\
-\end{array}$ & 3.66 & - \\
\hline $\begin{array}{l}\text { 28. How many } \\
\text { meaningful } \\
\text { relationships have you } \\
\text { had with women / } \\
\text { men? }\end{array}$ & 4.38 & - & 5.00 & - \\
\hline $\begin{array}{l}\text { 29. How interested are } \\
\text { you in talking with } \\
\text { women/ men? }\end{array}$ & 7.23 & - & 7.58 & - \\
\hline
\end{tabular}

*Note: General answers 1 = Agree a lot, 4 = Disagree a lot **\#29 10+ = a lot, $1=$ Not at all

On the other hand, in considering items that students 
showed relatively high levels of disagreement on (being over 2.50), six items $(7,9,16,22,23$, and 25) indicated that students were uneasy about relating to and understanding the opposite sex, and being confident in their discussions. While students also showed slight disagreement about whether or not they had achieved their goals, they also seemed to reject the idea of having feelings of rejection or having long pauses and silence in their speech.

The second hypothesis was proven false insofar that after three weeks of discussions for each group, results were mixed. There were 11 variables that students showed more agreement on, (1, 2, 3, 5, 9, 12, 19, 21, 22, 23, and 25) indicating that there was a positive outcome from the interactions. In short, unlike before, students were now able to share ideas without hesitation, conclude discussions pleasantly.

Likewise, they felt they could now relate to each other more easily, and as a result, they a better time talking to each other, smiling more and being more attentive, and confident. Results also showed slightly more agreement as to whether or not they had actually achieved their goals. There were, however, after these three weeks of interactions more disagreement shown on 12 items, but only five variables showed, significant (0.4) difference in change, such as perceiving tension, feeling uneasy in talking, perceiving long pauses and silence, having difficulty in expressing emotions, and finding common interests.

\section{DISCUSSION}

As [13] state attitudes are learned, and are difficult to unlearn in a few interactions as predispositions to respond in a favorable or in a negative manner is the result of past experiences. Attitude, nonetheless, is viewed as a latent variable, which is assumed to guide behavior. However, the results indicated that participants felt that they felt more positive towards interacting with the opposite sex (11 variables), yet, there were several troubling variables that reflected the stress of gendered discourse. As students felt it was still difficult to express themselves and to find common interests, it is apparent that they had problems in relating to each other. As a result, students felt some tension and uneasy with such discourse.

\section{CONCLUSION}

Comprehending gender differences in Japanese is demanding for learners of Japanese since these differences not only concern linguistic or paralinguistic features but also involve social expectations and variations depending on context. Moreover, these differences are dynamic in nature, as [14] notes, reflecting ever-changing characteristics of society. Thus, further research on gender fluency on Japanese L2 learners needs to take into account personality variables, context, status, and issues relating to familiarity.

As [15] note research on self-reports (and surveys) are useful in understanding the social and emotional reactions of youth, but more in-depth interviews and observations should be employed as well to better understand the social inhibitions and issues relating shyness. A factor analysis of this survey is the next step to further validate the overall structure and interrelationship of the variables. In short, it is also recommended that instructors focus providing on more varied and challenging interactions for students in order to become more motivated when talking to the opposite sex.

\section{Notes}

1. Article found at Japan Today: Retrieved at https://www.japantoday.com/smartphone/view/lifestyle/34of-japanese-men-afraid-of-their-female-colleaguesaccording-to-recent-poll

2. Article found at Japan Today: retrieved at https://www.japantoday.com/category/lifestyle/view/34-ofjapanese-men-afraid-of-their-female-colleagues-accordingto-recent-poll

3. Five Factor Model (FFM): retrieved at http://www.oxfordbibliographies.com/view/document/obo9780199828340/obo-9780199828340-0120.xml

4. Check www.genderfluency.com for corpus. The gendered videos, are available at: genderfluency.com

\section{APPENDIX}

A. GENDER FLUENCY INVENTORY SCHEMATIC

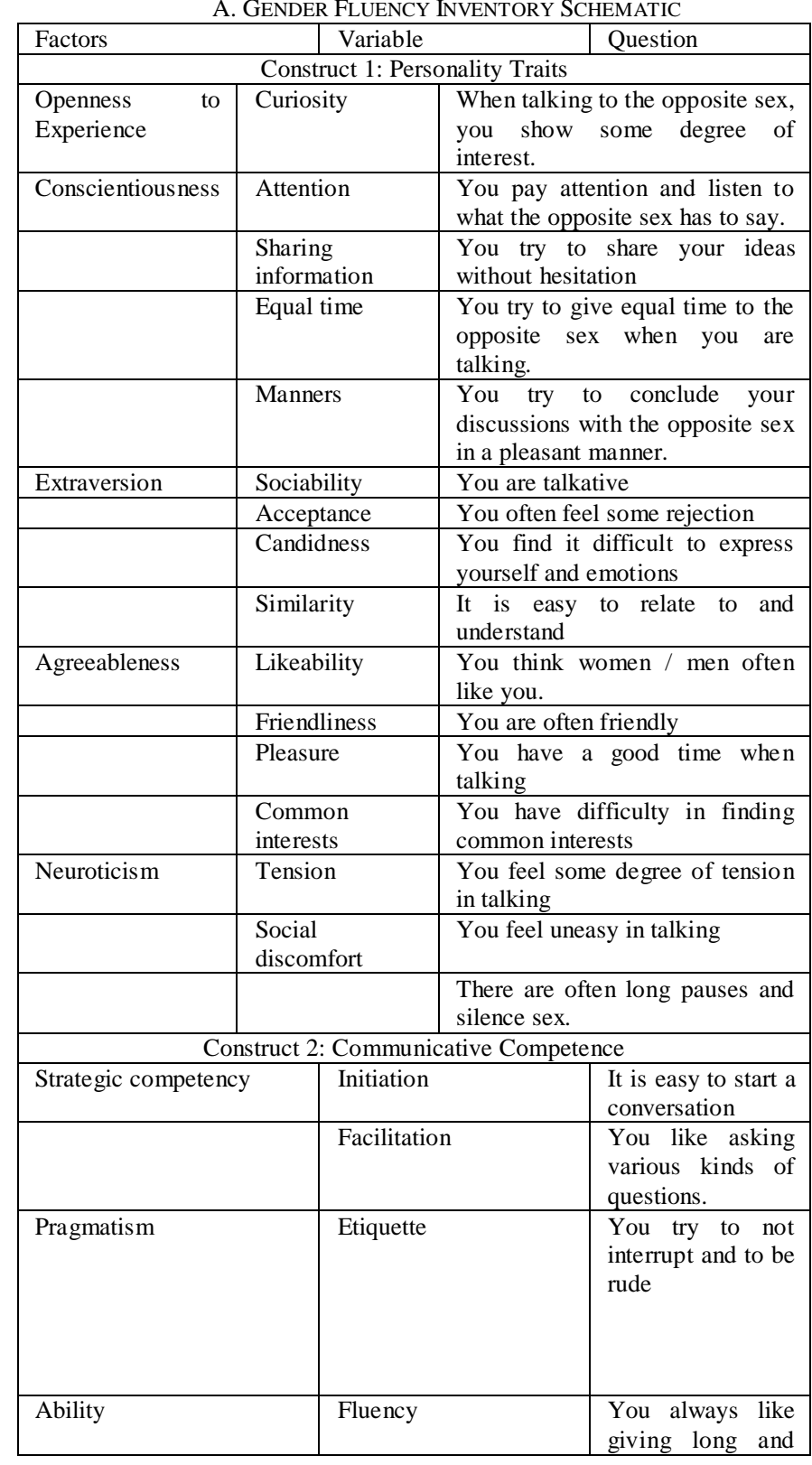




\begin{tabular}{|l|l|l|}
\hline & Nonverbal behavior & $\begin{array}{l}\text { informative } \\
\text { replies and } \\
\text { sharing opinions. }\end{array}$ \\
\hline & $\begin{array}{l}\text { You try to smile, } \\
\text { be attentive, } \\
\text { making eye } \\
\text { occasional eye } \\
\text { contact, and } \\
\text { gestures }\end{array}$ \\
\hline & Comprehension & $\begin{array}{l}\text { You find it easier } \\
\text { to understand the } \\
\text { opposite sex. }\end{array}$ \\
\hline Confidence & Construct 3: Morale & $\begin{array}{l}\text { You are confident } \\
\text { about using } \\
\text { English }\end{array}$ \\
\hline Satisfaction & L2 Usage & $\begin{array}{l}\text { You are not shy } \\
\text { You feel that you } \\
\text { can always make } \\
\text { your point and } \\
\text { achieve your } \\
\text { goals }\end{array}$ \\
\hline & Inhibition & $\begin{array}{l}\text { You are motivated } \\
\text { to have follow-up } \\
\text { discussion }\end{array}$ \\
\hline
\end{tabular}

\section{ACKNOWLEDGMENT}

This research is supported by the Grant-in-Aid for Scientific Research (KAKENHI) of the Ministry of Education, Culture, Sports, Science, and Technology in Japan (No. 15K02788). I also want to thank Jose Cruz, a lecturer at Kitakyushu City University for his help in video and audio recording.

\section{REFERENCES}

[1] L. Henderson and P. Zimbardo. (1999). Comorbidity in chronic shyness. The Shyness Institute, Portola Valley, California. [Online]. Available:

http://shyness.com/wpcontent/uploads/1999/Comorbidity.pdf

[2] M. Leary, "Affective and behavioral components of shyness: Implications for theory, measurement, and research," in Shyness: Perspectives on Research and Treatment, W. H. Jones, J. M. Cheeck, and S. R. Briggs, Eds. New York: Plenum Press. 1986, pp. 27-38.

[3] P. Pilkonis, "The behavioral consequences of shyness," Journal of Personality, vol. 45, no. 4, pp. 596-611, 1977.

[4] K. Rubin, R. Coplan, and J. Bowker, "Social withdrawal in childhood,” Annual Review of Psychology, vol. 60, 2009.

[5] G. Bohlin, B. Hagekull, and K. Anderson, "Behavioral inhibition as a precursor of peer social competence in early school age: The interplay with attachment and nonparental care," Merrill Palmer Quarterly, vol. 51, no. 1, pp. 11-19, 2005.
[6] M. Lewin, D. McNeil, and J. Lipson, "Enduring without avoiding: Pauses and verbal dysfluencies in public speaking fear," Journal of Psychopathology and Behavioral Assessment, vol. 18, no. 4, 1996, pp. 387-402.

[7] P. Zimbardo, Shyness: What it is, What to do about it. Reading, MA: Addison-Wesley, 1977.

[8] Y. Aizawa and M. Whatley "Gender, shyness, and individualismcollectivism: A cross-cultural study,” Race, Gender \& Class, vol. 13, no. 1-2, pp. 7-25, 2006.

[9] M. Crawford and R. Chaffin, "Effects of gender and topic on speech style,” Journal of Psycholinguistic Research, vol. 16, no. 1, pp. 83-89, 1986.

[10] J. Heuchert and D. McNair, Profile of Mood States, Second Edition, Multi-health Systems Inc.: Ontario, Canada, Japanese edition published by Kaneko Shobo Co. Ltd., 2015.

[11] J. Misumi, The Behavioral Science of Leadership: An Interdisciplinary Japanese Research Program, Ann Arbor: University of Michigan, 1985.

[12] R. Long and H. Inoue, "Exploring teachers' leadership behavior and morale through student attitudes," Kyushu Institute of Technology Bulletin, vol. 52, pp. 1-20, 2004.

[13] M. Fishbein and I. Ajzen, Belief, Attitude, Intention, and Behavior: An Introduction to Theory and Research, Reading, MA: AddisonWesley, 1975.

[14] M. Yoshida. (2011). "Gendered characteristics of female learners' conversational Japanese," in New Voices in Japanese Studies. [Online]. 5, pp. 103-129. Available: http://dx.doi.org/10.21159/nv.05.05

[15] N. Eisenberg and R. Fabes, "Prosocial development," in Handbook of Child Psychology: Vol. 3. Social, Emotional, and Personality Development, 5th ed. W. Damon \& N. Eisenberg, Eds., New York: Wiley, 1998, pp. 701-778.

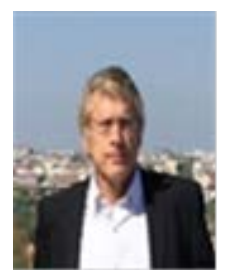

Robert Long was born in March, 1960, in Delaware, Ohio. He has a bachelors 1981, and masters in English education 1983, (University of Florida) and a specialist degree in education multilingual/multicultural (Florida State University) 1993. He has worked in Hiroshima Shudo University, and Kyushu Institute of Technology (22 years) where he has been the foreign lecturer and is now currently an associate professor. He has written several EFL textbooks concerning oral communication and technical English. His past work include articles such as (1) "Fluency and dysfluency in same-sex interactions: Preliminary Results" in Proc. the International Journal of Arts and Sciences Conference, pp. 227-238, 2016; (2) “Complexity and fluency indicators of "Good" speakers" Robert Long. JALT2013 Proceedings, pp. 163-175 and (3) "A Longitudinal study of novice-level changes in fluency and accuracy in student monologues," (2012), Robert Long, English Language Teaching, vol. 5, no. 10, pp. 129-137. His most recent textbook is Connections: Understanding Social and Cultural Issues, 3rd ed. Perceptia Press. ISBN: 4-939130-91-6. He is currently content editor for KASELE Journal (2004 - present), past editor of the Language teacher (currently on Editorial Board) and is a member of JALT and KASELE. He manages his fluency website so as to provide a resource for teachers who are concerned with fluency issues. 